\title{
HIV CONTINUUM AT A LARGE URBAN HIV CENTRE: DOING WELL BUT SOME GROUPS DOING BETTER THAN OTHERS
}

\section{GUIDE CLINIC}

\section{Background:}

The UNAIDS 90-90-90 treatment goal aims to have 90\% PLHIV diagnosed, $90 \%$ of those diagnosed on HAART and $90 \%$ of those receiving HAART to be virally suppressed. ${ }^{1}$ In line with international guidelines, antiretroviral therapy (ART) is recommended for all people living with HIV in Ireland. ${ }^{2}$ Based on the findings of the European Centre for Disease Control (ECDC) Dublin Declaration report on the continuum in 2015, the ECDC expert meeting recommended monitoring a four-stage continuum that is directly relevant in the European region ${ }^{3}$ :

Stage 1 - the estimated number of all PLHIV; Stage 2 - the number of all PLHIV who have been diagnosed;

Stage 3 - the number on PLHIV who have been diagnosed and who are on ART;

Stage 4 - the number of PLHIV on ART who are virally suppressed.

\section{Methods:}

At a large urban, adult HIV service, nationally agreed definitions for stages 2, 3 and 4 of the ECDC HIV care continuum were assessed

A list of attendees to a general HIV outpatient department between $1^{\text {st }}$ January and $31^{\text {st }}$ December 2017 was generated. Using this database and the electronic patient record system, information on patient gender, HIV risk group, ART treatment status and HIV viral load (VL) was collected.

\section{Results:}

Between $1^{\text {st }}$ January and $31^{\text {st }}$ December 2017, 2772 attended for at least one HIV clinic appointment. Of these attendees, 50\% were MSM, 35\% Heterosexual, $13 \%$ PWID, $2 \%$ other. Overall 2744(98\%) were on ART of whom 2635(96\%) and 2509(91\%) were suppressed to $<200$ copies $/ \mathrm{ml}$ and $<40$ copies $/ \mathrm{ml}$ respectively. When the numbers were analysed by risk group, the MSM group faired best with almost all those attending on HAART and achieving suppression rates of $95 \%$. Conversely, the PWID group only achieved suppression rates $<40 \mathrm{cpm}$ in $77.9 \%$ despite the majority of these patients receiving HAART.

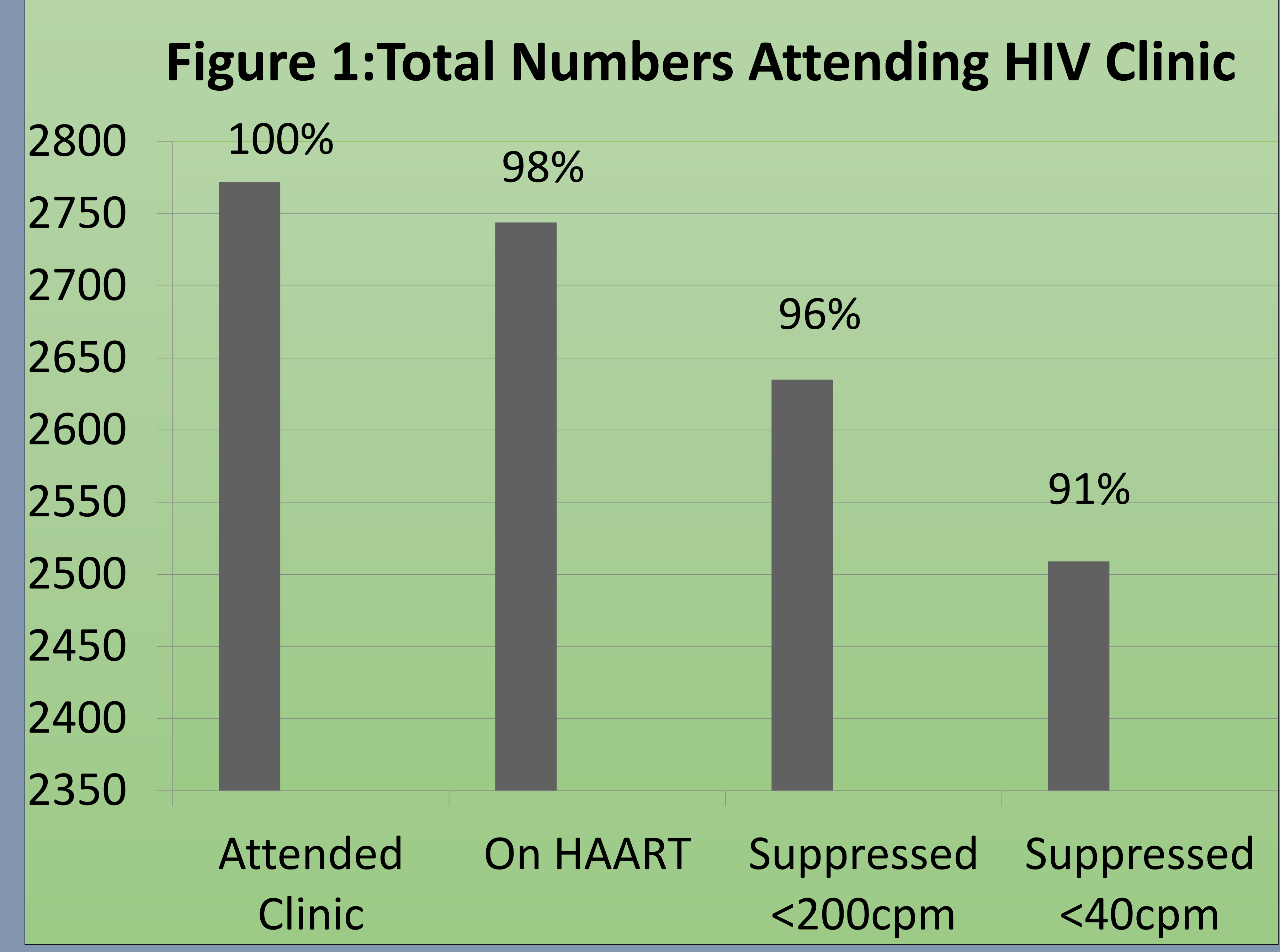

Figure 2:Risk Groups Attending HIV Clinic

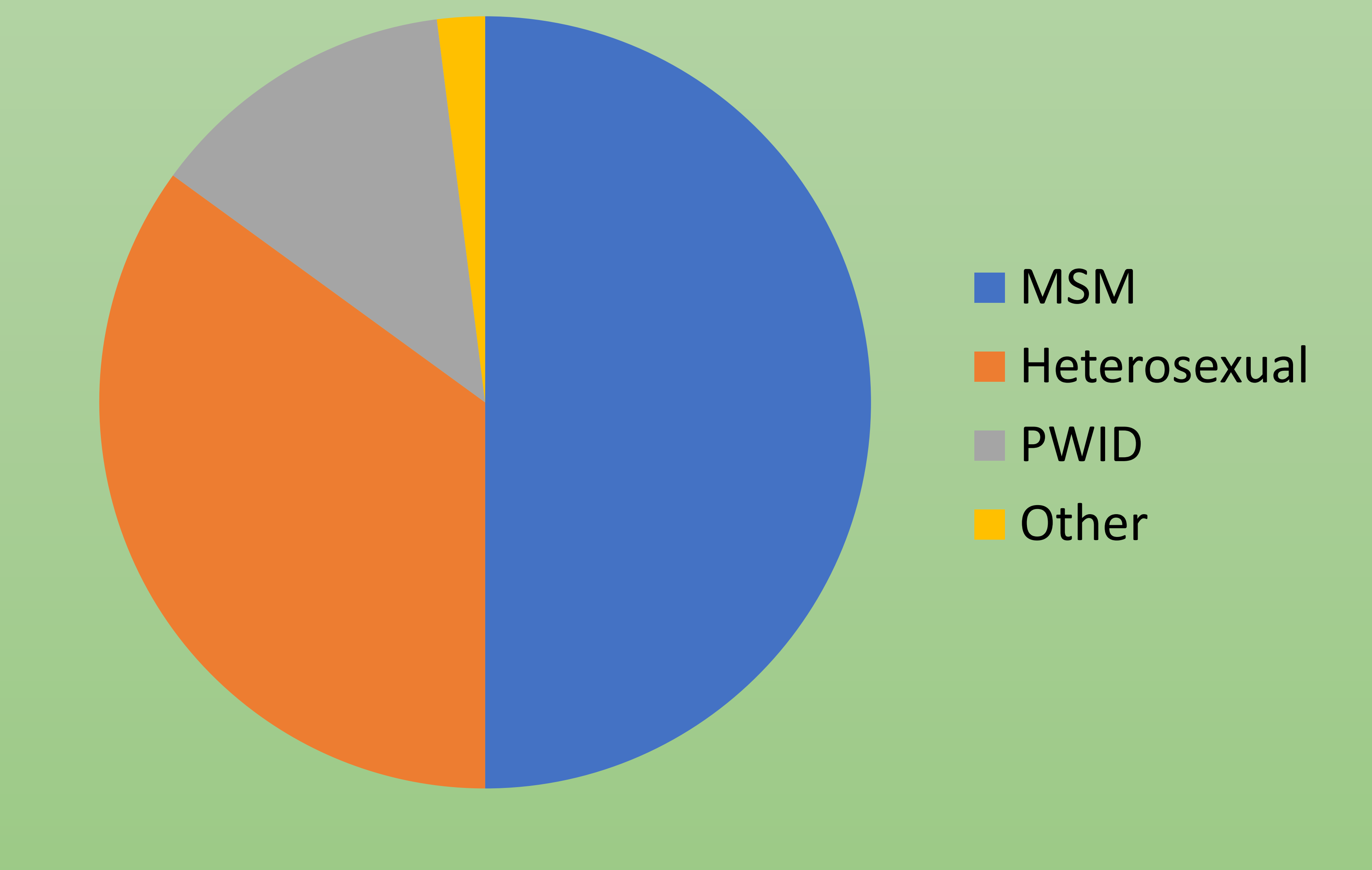

Table 1:Viral Suppression by Risk Group

\begin{tabular}{|c|c|c|c|}
\hline Risk & HAART & $\begin{array}{c}\text { HIV VL } \\
<200 \mathrm{cpm}\end{array}$ & $\begin{array}{c}\text { HIV VL } \\
<40 \mathrm{cpm}\end{array}$ \\
\hline MSM & $99.4 \%$ & $98.5 \%$ & $95 \%$ \\
\hline Heterosexual & $98 \%$ & $95.6 \%$ & $88.4 \%$ \\
\hline PWID & $99.4 \%$ & $85.7 \%$ & $77.9 \%$ \\
\hline Other & $98.1 \%$ & $94.4 \%$ & $90.7 \%$ \\
\hline
\end{tabular}

\section{Conclusion:}

At this large urban HIV clinic, all risk groups have reached UNAIDS ART targets. Viral suppression targets are not yet being met in the PWID group despite most patients in this group receiving treatment. Further research into understanding why this group are not meeting viral suppression targets is needed. 